\title{
SPECIFIC FEATURES OF IGNITION AND FLAMEHOLDING OF HYDROCARBON FUELS IN HIGH-SPEED FLOW
}

\author{
M. Goldfeld \\ Institute of Theoretical and Applied Mechanics \\ Siberian Branch of the Russian Academy of Sciences \\ 4/1 Institutskaya Str., Novosibirsk 630090, Russia
}

The paper describes the results of experimental investigations of a supersonic combustion chamber with solid and discrete cavities at the entrance Mach numbers of 3 and 3.5. Kerosene and propane were used as fuel. The conditions required for self-ignition and intense combustion of the fuels were determined. The possibility of efficient combustion in a supersonic flow was demonstrated. Analysis of applicability of existing criteria predicting the conditions of self-ignition and extinction of combustion has been performed based on the experimental results obtained.

\section{INTRODUCTION}

Scramjet engine is one of the candidates for hypersonic flight propulsion system, which will be used in a wide range of flight Mach numbers from 4 to 12 or higher. Therefore, it should be well operated in dual-mode and scramjet mode depending on the flight Mach number [1]. Originally, a lot of studies were performed for hydrogen-fuelled concepts of a supersonic combustion chamber, primarily for space transportation systems. In this case, the upper speed limit lies in the range of Mach numbers 12-16 [2,3]. There were also studies on hydrocarbon-fuelled scramjets with the upper speed limit on flight Mach number established in the Mach range of 8-10 [4]. In either case, the flow velocity at the entrance of combustor can achieve a Mach number of 4-5. Liquid hydrocarbons are attractive solutions for the hypersonic flight in view of their high volumetric energy content, lower cost, and relative simplicity of operational utilization. The difficulties of the use of hydrocarbon fuels as compared with gaseous systems are caused by the longer residence times required for vaporization, mixing, and completion of chemical reactions [5-7]. In general, the key elements for successful operation 
of a liquid hydrocarbon-fuelled combustion chambers include deeper fuel spray penetration into air flow for better mixing, generation of smaller liquid droplets for faster evaporation, and effective flame holding mechanisms with minimal drag. In practical scramjet engines, a liquid hydrocarbon fuel can also be used to cool the engine flow path and absorb a part of heat imposed by the flight environment.

It is widely recognized that the performance of a supersonic combustor is substantially influenced by fuel injection schemes [8-10] and flame-holding systems $[11,12]$. Several fuel-injection approaches, such as strut, wall, ramp (aeroramp), etc. have been proposed and extensively investigated [13-15]. Efficient mixing is the main objective in all these injection strategies since the total pressure loss and drag (resulting in overall thrust loss) are associated with these devices. The cavity-based flameholder has been widely used and studied $[11,12,16-18]$ due to its advantages in stabilizing the flame while minimizing the total pressure loss and eliminating the requirement for additional thermal protection to the flameholder. Many studies were focused on understanding the flame-holding mechanism of a single cavity in supersonic combustors and optimizing the cavity design $[11,13,16,19]$. In some studies, multiple cavities were used in supersonic combustors [20,21].

Numerous experiments have been carried out to study the effect of cavity geometric parameters, namely, cavity length-to-depth ratio, offset ratio, aft-wall angle, and other parameters, such as injection pressure, injection location, passive and direct fuelling, and back pressure on the mixing and combustion characteristics of different fuels (hydrogen and hydrocarbons). In general, gaseous fuels, especially, hydrogen, are preferred over liquid hydrocarbon fuels because evaporation of the fuel is not necessary and, in addition, their diffusivity is higher. Based on these considerations, the cavity-based flameholding scheme was adopted in the present study in order to extend the region of configurations which were not examined earlier.

The relatively slower reaction of hydrocarbon fuels can be accelerated by using gaseous pilot flame or different combinations of struts or/and wall injection of both main hydrocarbon fuel and hydrogen pilot torch [22-25]. Fuel preheating can also accelerate mixing and ignition, particularly, if the level of heating and combustor conditions can ensure flash vaporization [15,21]. Evidently, such conditions can only be realized at high flight speeds. In recent years, the investigation of hydrocarbon fuel combustion attained ever-increasing interest $[19,21,26]$. Nevertheless, it should be noted that the most frequent experimental studies of combustion chambers were performed at the entrance Mach numbers of 1.5-2.5 for hydrogen-fuelled ramjets $[4-6,13]$.

Many studies were focused on numerical simulation of reacting and nonreacting flows in supersonic combustor for understanding the ignition process and flameholding mechanism and for their optimization [27-32]. Calculations were carried out to simulate the physical processes occurring in the combustor flow 
field and to determine the effects of different fuel injection schemes on the overall scramjet combustion efficiency [27,31]. Different arrangements were compared in terms of species mixing efficiency and overall combustion optimization. The numerical approach is based on solving the full three-dimensional (3D) NavierStokes equations supplemented with combustion models of different complexity with different chemical reactions and chemical species [28]. They could include a rate-controlling kinetic mechanism for combustion of different fuels in air. The chemical model is directly coupled with a turbulence model. In some cases, the location of fuel injectors and the angle of injector orifices are varied to determine the optimum injection scheme. All combustor configurations include a backwardfacing step, cavity, or struts [32] and their combinations [31] to provide flameholding and stabilization in the combustor; for example, mixing efficiencies are predicted for 10 different injection schemes. The comparative results indicate that the fuel injection configuration with opposing injector pairs located in the cavity, on the step, and the ramp are the most efficient, resulting in 73 percent combustion efficiency [30]. Details of the flow field inside the combustor as well as variation of mixing efficiency, combustion efficiency, and total pressure loss along the combustor length are presented and discussed in [28].

The obtained numerical results provide important information to aid in the understanding of physical processes that dominate the flow. Review of combustion simulation in supersonic combustor (Scramjet) can be found in [33].

At present, there is no universal theory, which would explain the mechanism of fuel ignition and flame stabilization by flame holders of different shape, which form the flows with recirculation zones. In spite of numerous studies of combustion chambers with supersonic flow, up to now, there are no acceptable methods of calculation, which would allow predicting reliably the mechanism and conditions of ignition and combustion stabilization. As a rule, the calculation methods are based on empirical or semiempirical relations, which use the experimental results $[7,31,34]$. Considering the complexity of the phenomenon and multiparametric character of the problem, these methods have limited applicability and do not always provide satisfactory results.

The present work is a continuation of investigations of combustion in supersonic flows $[35,36]$. The main purposes of the investigation were as follows:

- determine the conditions of hot kerosene ignition with different flame holder shapes;

- study the effect of different ways of fuel injection on ignition efficacy;

- compare the effectiveness of ignition and stabilization of liquid and gaseous fuels; and

- analyze self-ignition and flame propagation in a supersonic combustor. 


\section{COMBUSTOR MODEL AND EXPERIMENTAL SETUP}

The scheme of the model, the installation of injectors, and location of cavities are presented in Fig. 1. The channel dimensions at the injector exit are $100 \times 100 \mathrm{~mm}$, including the steps with a height of $H=25 \mathrm{~mm}$ on the top and bottom walls. A rearward-facing step and an additional wall with a height of $16 \mathrm{~mm}$ form the cavity-based flame holder. As a result, the open cavity with a length-to-depth ratio of $L / h=2.5$ is obtained. The solid and discrete back walls are used that specify the name of a cavity type. The length of elements (posts) of a discrete wall is equal to the width of an injector, i. e., $l=b=12 \mathrm{~mm}$. At tests, two types of fuel are used: kerosene and propane. The majority of experiments are carried out with kerosene, which is heated up to $560-580 \mathrm{~K}$.

The number of injectors is four. They are similar to those proposed in [37]. Injector configuration and its dimensions are described in [35]. Fuel is injected at the same angle as the injector ramp angle $\omega=8^{\circ}$. A specific feature of this construction is the possibility of fast and convenient changes of injectors, variation of the Mach number and other experimental conditions. The injectors are developed as replaceable elements. Such a construction enhances considerably the experimental capabilities of the model.

Injectors of different geometry can be also installed. Each injector has two nozzles for fuel injection. One of the injectors is divided into two parts, and the

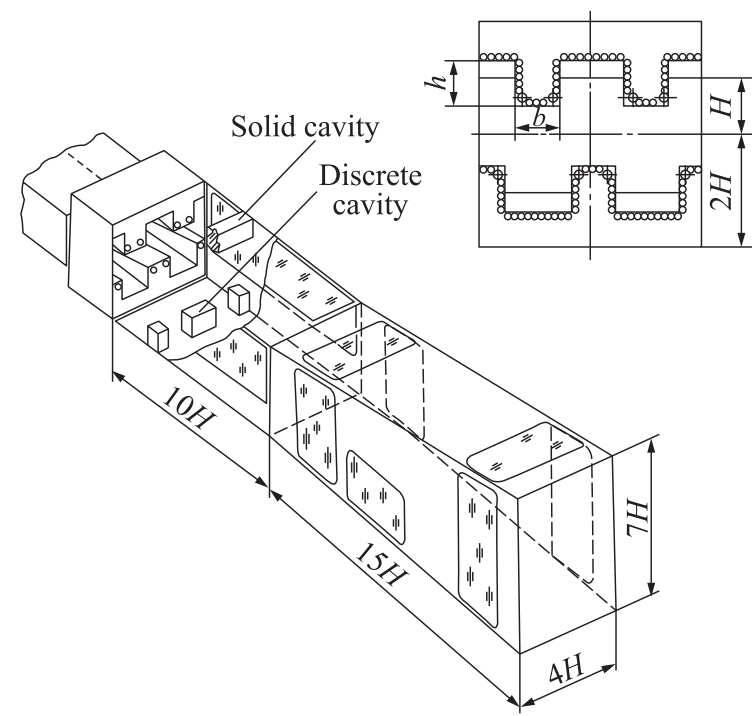

Figure 1 Scheme of the model 
resultant "half-injectors" are located in the lower corners of the injector section. The nozzles for fuel injection are located as close as possible to the upper and side surfaces on the injector back flat face. The special holes in the insulator and injector section are made and a fuel supply system delivers fuel into the separation zone / shear layer behind injectors and into the boundary layer ahead of the injector ramps.

The combustion chamber has a $3 \mathrm{D}$ configuration. The modification of the combustion chamber geometry is basically intended to choose such geometry of the injectors and flame holders, which might guarantee stable combustion within the wide range of flight conditions. In previous experiments, it was found [36] that the solid cavity (across all injector section) was not effective enough and did not provide the required effectiveness of kerosene combustion. Then, the combustion chamber was tested also with a discrete (local) cavity. The local cavity was formed behind each injector ramp by means of a post.

Investigations were carried out in the connected pipe mode. First, a prechamber of a hot-shot wind tunnel IT-302M was used as a source of hot gas [38]. Such approach allows one to get a high-enthalpy flow with high pressure and temperature at the combustor entrance. The specific feature of this wind tunnel is the decrease of flow parameters during the operation time (100-120 ms). Therefore, a large number of runs were carried out with the pressure multiplicator to maintain a constant value of equivalence ratio (ER). Models were tested at the following conditions at the duct entrance: Mach numbers $\mathrm{M}_{\mathrm{en}}=2.97$ and 3.49, total temperature $T_{t}$ from 2000 to $3000 \mathrm{~K}$, static pressure $P_{\mathrm{en}}=0.08-0.25 \mathrm{MPa}$, and fuel-air ER from 0.25 to 1.4.

\section{MEASUREMENTS}

During the tests, the following parameters were measured: the total flow parameters in the first and second prechambers of wind tunnel IT-302M; air and fuel flow rates; distributions of static pressure and heat flux in the model channel; Pitot pressure and temperature at model exit; base pressure distribution on the back step of injector device and on the forward/backward wall of the cavity post; and flow visualization at $\mathrm{CH}$ and $\mathrm{OH}$-radicals wavelengths and in the visible range. Large amount of the measured stations (more than 120) allowed detailed distributions of static pressure and heat flux including base pressure and pressure in transversal directions to be obtained.

\section{RESULTS AND DISCUSSION}

Comparison of pressure distribution along the combustion chamber with solid and discrete cavities with kerosene combustion confirmed that the modification of cavity caused changes in the distributions of the base pressure and pressure 
along the channel length. The maximum level of pressure growth in the combustion chamber appeared to depend on the cavity type. Moreover, the character of the pressure growth was different. The maximum pressure level in the combustion chamber with the discrete cavity was reached at a distance of about $150 \mathrm{~mm}$ from the fuel injectors (Fig. 2a). One can see that the pressure increases fast in this part of the combustion chamber and this growth occurs not only in the constant cross-section part but also in the base region, including the pressure on the injector insertion. Comparison of pressure level at different time instants demonstrates that the maximum pressure is already reached at $30 \mathrm{~ms}$ and remains constant up to approximately $70 \mathrm{~ms}$, i. e., up to the end of setup operation time.

The maximum pressure level in the combustion chamber with the solid cavity was reached at approximately $x=235 \mathrm{~mm}$ (Fig. $2 b$ ), i. e., at the end of combus-

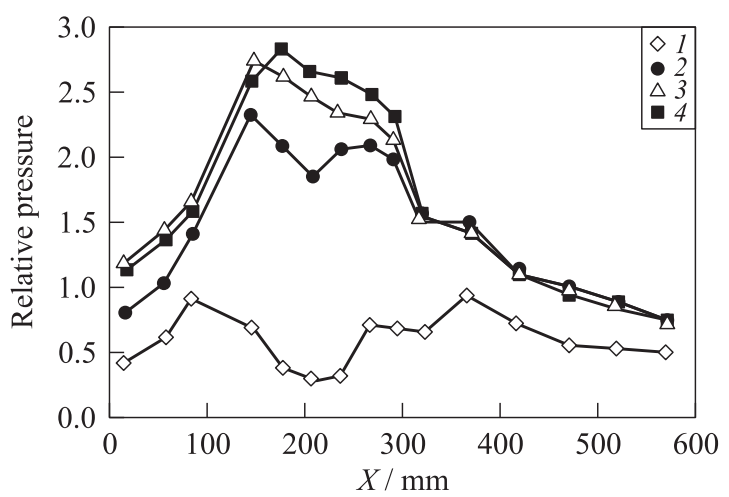

(a)

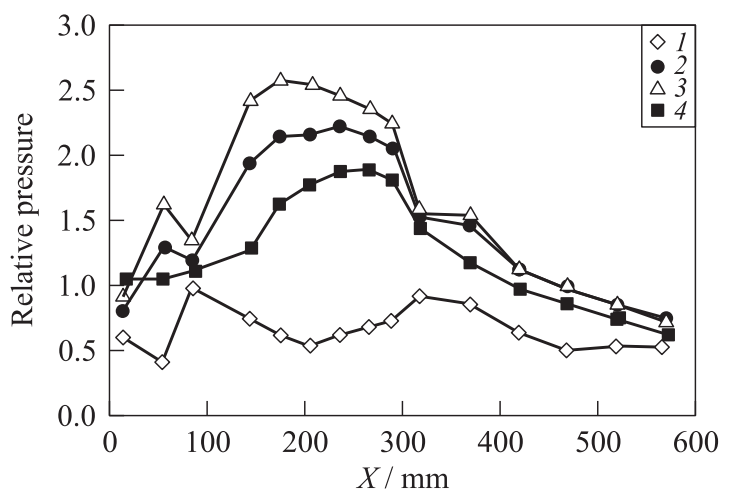

(b)

Figure 2 Pressure distribution on the bottom wall in the channels with discrete $(a)$ and solid (b) cavities at $\mathrm{M}=3: 1-10 \mathrm{~ms} ; 2-30 ; 3-40$; and $4-60 \mathrm{~ms}$ 
tor with constant cross section $(240 \mathrm{~mm})$. Comparison of data for combustion chambers with discrete and solid cavities demonstrates that in the first case, the static pressure was $15 \%$ higher than in the chamber with solid cavity. Another feature of the process in the combustion chamber with solid cavity consists in the fact that at intense combustion, the pressure plateau was not obtained. A similar qualitative difference for the two cavity types remained also on the top wall. The pressure in the channel with the solid cavity rose almost everywhere in the constant cross section. These data also show that the local cavity configuration may influence significantly the pressure distribution in the channel and the base pressure changes. This follows from the comparison of the results for the top and bottom walls.

The change of pressure in the base region behind the injector section and behind the one in the cavity has a complicated nature due to the $3 \mathrm{D}$ nature of the flow caused by interaction of the jet-cavity posts, shock waves, and expansion waves. Therefore, three characteristic sections on the bottom (index " $b$ ") and top (index " $t$ ") walls can be considered. Measured in the experiments were: the pressure on the back-face injector section $(Z=0 \mathrm{~mm})$; the pressure on the backward facing step between injectors $(Z=25 \mathrm{~mm})$; and the pressure on the half-injector back-face near sidewall $(Z=45 \mathrm{~mm})$.

The time dependence of the relative pressure testifies that the delay of "kindling" of combustor takes place (see Fig. $3 b$ ). Time "kindling" is time, during which pressure remains low and approximately constant [39], and intense combustion is not realized. Only beginning with the 25 th millisecond, the pressure starts weakly to increase. One can see that in this case, the base pressure in the time history does not change up to $35 \mathrm{~ms}$. At intense combustion $(t>35 \mathrm{~ms})$, the pressure increases and has high nonuniformity in transversal direction. The base pressure in the combustor with the solid cavity increases twice only at the end of setup operation. Figure $3 b$ demonstrates also that base pressure on the backward injector wall (curve 3, empty signs) of bottom injector section was, on the average, higher by $20 \%-30 \%$ than on top injector section.

The application of the discrete cavity behind injectors entails significant growth of the base pressure. This is evident from the comparison of the data in Figs. $3 a$ and $3 b$. The base pressure in the combustion chamber with the discrete cavity is increasing during the whole mode of the combustion chamber operation. The base pressure in this case rises fast by a factor of 3.5-4 and has a clear plateau of pressure during $20 \mathrm{~ms}$. The base pressure was different on the top and bottom walls of section and on backward facing steps between them. At intense combustion, high nonuniformity of pressure distribution in transversal direction remained approximately on the same level as in the combustion chamber with solid cavity.

As a result of kerosene combustion, pressure increase on the combustor walls occurs and certain pressure equalizing over the cavity width but the pressure on the bottom wall of the cavity (floor of cavity) has changed weakly. Furthermore, 


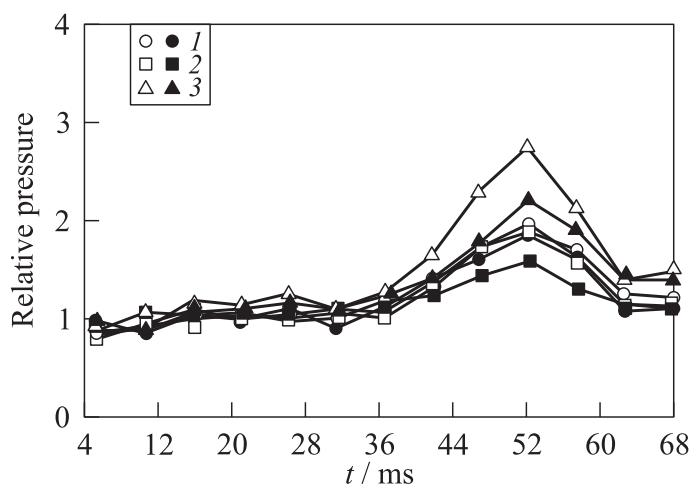

(a)

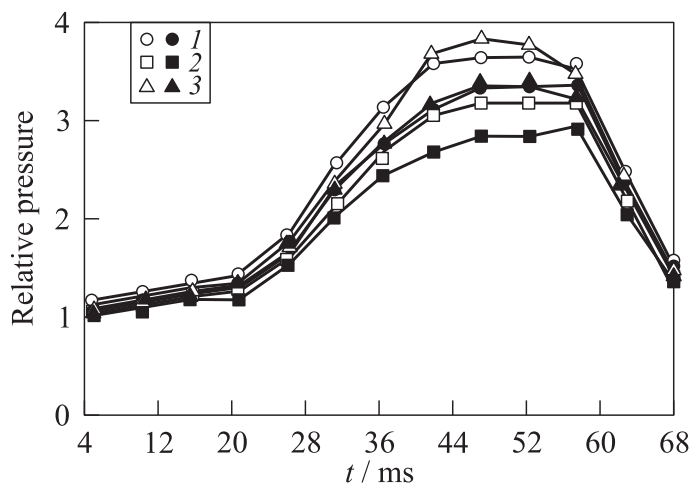

(b)

Figure 3 Relative base pressure in the channels with discrete $(a)$ and solid (b) cavities at $\mathrm{M}=3: 1-Z=45 \mathrm{~mm} ; 2-25$; and $3-Z=0 \mathrm{~mm}$. Empty signs refer to bottom walls $\left(Z_{b}\right)$ and filled signs refer to top walls $\left(Z_{t}\right)$

some reduction of the average pressure on the cavity wall occured. It can be the consequence of the ejecting effect of fuel jets.

The data obtained showed that the flow structure in the solid cavity was changed weakly during the combustion and had almost no effect upon the ignition process. This can be seen from the comparison of visualization of a flow in the channel with cavity without fuel supply and at combustion of kerosene (Figs. $4 a$ and $4 b$ ). Visualization of the flow with combustion demonstrates that disintegration of kerosene jets occurs behind a cavity (see Fig. 4b) since there is no increase of temperature in the solid cavity. With a discrete cavity (Fig. 4c), there is almost full disintegration of kerosene jets, their screening effect disappears and intense combustion is observed. In this case, the flow becomes transonic or even subsonic (without shock waves). 
One can assume that ignition and combustion stabilization occur behind the back solid wall (behind post). The pressure on the back wall of the cavity post has been increasing more than 3 times during combustion. The pressure growth on the back wall of the bottom cavity post was somewhat higher than that on the top wall that agrees with the results of pressure measurement on the backward wall of injector section. This distinction depends on different geometrical configurations of the discrete cavity on the top and bottom walls of the combustion chamber. The results of the pressure measurement in the cavities confirmed this assumption. It was revealed that pressure on the back wall of solid cavity has changed slightly and achieved the maximum value only at the end of combustion. The character of pressure distribution on the back wall of a discrete cavity (front wall of cavity post) was different but its maximum level differed weakly from the pressure on the back wall of the solid cavity.

For assessing the combustion effectiveness, the growth of the static pressure in the combustor at combustion conditions is compared to the corresponding pressure in the "cold" experiment (without fuel supply). These data for the combustor with solid cavity are presented in Fig. $5 b$. Application of solid cavity is accompanied by moderate growth of relative static pressure approximately by a factor of 3 for the whole channel. Simultaneously, it can be seen that the increase in pressure continues only until the 40th millisecond, and then pressure decreases. Pressure distribution and corresponding flow visualization have shown that intense combustion took place only in channels with constant cross section. In the divergent part of the combustor, the static pressure

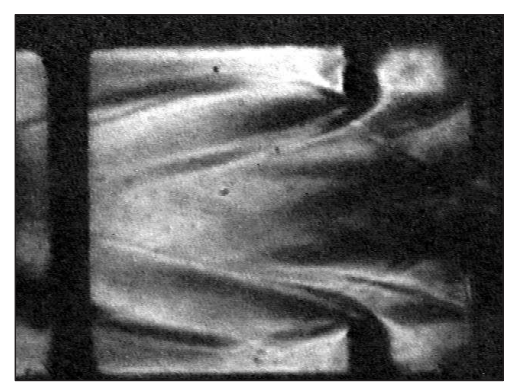

(a)

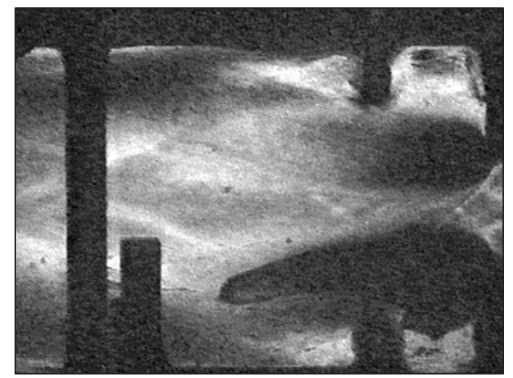

(b)

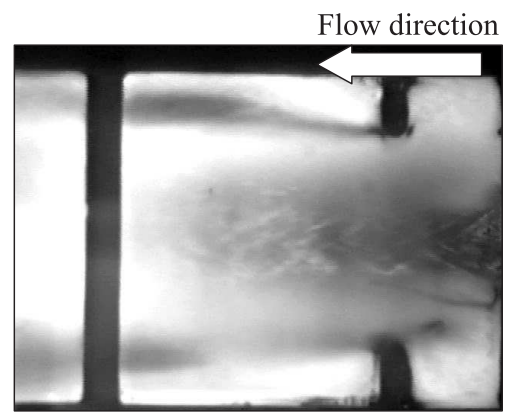

(c)

Figure 4 Schlieren visualization of flow in combustor at $\mathrm{M}=3$ (different cavity, heated kerosene): (a) without fuel supply; (b) solid cavity; and (c) discrete cavity 


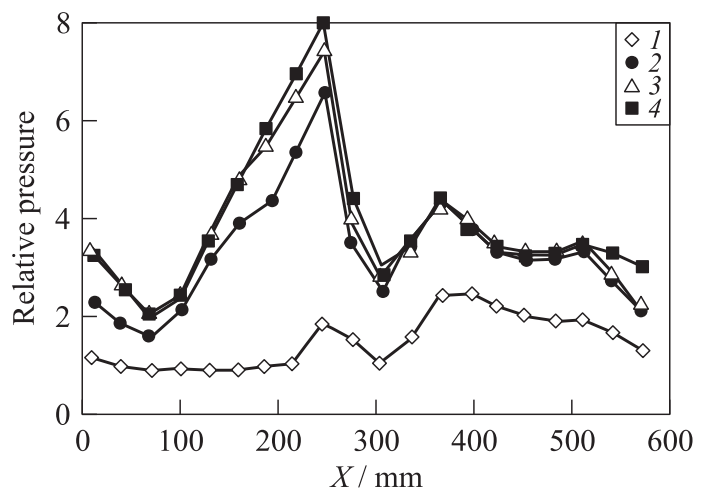

(a)

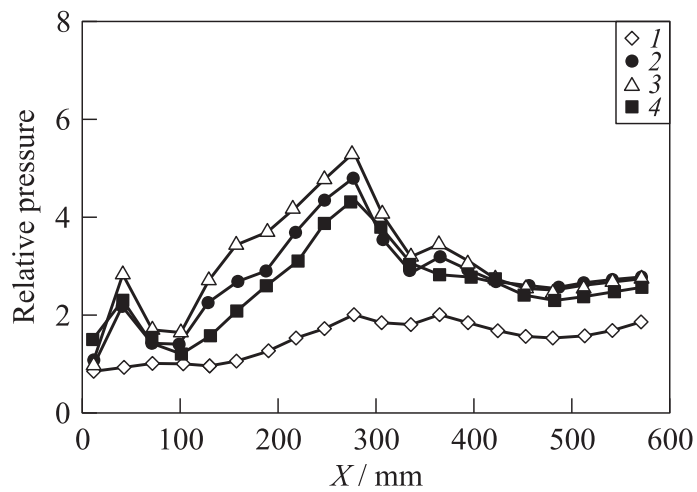

(b)

Figure 5 Relative pressure distribution on the bottom walls of the combustor with discrete $(a)$ and solid $(b)$ cavities at $\mathrm{M}=3: 1-10 \mathrm{~ms} ; 2-30 ; 3-40$; and $4-$ $60 \mathrm{~ms}$

was significantly lower, which is the evidence of a local character of combustion in the channel.

The solid cavity of the investigated geometry did not virtually affect the ignition and combustion stabilization. This result may be conceivably explained by the absence of fuel in the cavity and by the screening effects of air and fuel jets. This phenomenon has already been observed before in the study of single injectors of various configurations [35]. Actually, the application of cavites of such a shape leads only to the increasing of drag of the combustion chamber. Actually, the recirculation zone behind the cavity plays the role of a flame holder like a backward-facing step.

Application of the discrete cavity results in the pressure growth at kerosene combustion not only in the base region, but also over the whole length of com- 


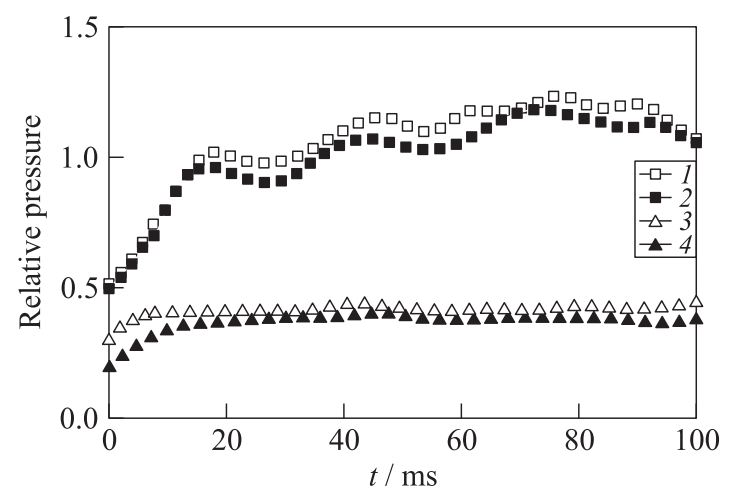

Figure 6 Time histories of the average relative pressure on the posts of solid and discrete cavities: $1-\mathrm{SC} 1 ; 2-\mathrm{SC} 2 ; 3-\mathrm{DC} 1$; and $4-\mathrm{DC} 2$

bustion chamber. The growth of the static pressure in the combustion chamber with discrete cavity compared to the corresponding pressure in the "cold" run (without fuel) is presented in Fig. $5 a$. One can see that in experiments with discrete cavity, the maximum pressure was approximately $60 \%$ higher than in the combustion chamber with solid cavity over the whole length of the combustion chamber, including its expanding section at $x>240 \mathrm{~mm}$. Such a character of pressure distribution remained on the top wall of the model as well. Flow visualization confirmed that combustion was spread over the whole combustor and retained for more than $70 \mathrm{~ms}$.

Use of the discrete cavity allowed speeding up the "kindling" of the combustion chamber and flame propagation over the whole channel. Consequently, the static pressure in the base region increased more than by a factor of 2 . This process is accompanied by a significant, more than $30 \%$, growth of the average pressure over the whole combustor length.

It is evident that the total drag of the cavity post depends on the relation between pressures on front and back surfaces of the posts and their longitudinal and transversal nonuniformity. The results of determination of the average pressure on the post surfaces for solid wall (SC - solid cavity) and for separate posts (DC - discrete cavity) are presented in Fig. 6.

Comparison of the pressure distributions for two cavities demonstrates that pressure on the posts forming the discrete cavity was much lower (by a factor of 4-5) than the pressure on the back post of the solid cavity. One may expect that the drag of the cavity post has to be also significantly lower. One can see that the difference in pressure values on the bottom (SC1 and DC1) and top (SC2 and DC2) walls was not large. However, the pressure on the top wall was always slightly higher (SC1 and DC1). 
Investigation of the combustion chamber without cavity was carried out to compare the effectiveness of ignition and flame stabilization. In these tests, fuel was injected into the shear layer and into the base region (rim injection, see Fig. 1). The tests of the model were carried out with two fuel supply systems. The main part of the fuel was injected through injector ramps like in the tests with the cavity and, in addition, the smaller part of the fuel (up to 10\%), was injected in parallel to the main stream in the isolator section. The total fuel-air ER was close to 1 .

The fundamental conclusion consists in the fact that kerosene ignition and combustion were not observed when the simultaneous kerosene injection into the flow core and the base region of no-cavity combustion chamber was carried out. In these cases, the pressure distribution along the model channel differs weakly from the pressure distribution in the test without fuel supply. Kerosene ignition and combustion did not also occur in the tests without fuel injection into the base region of the injectors. Installation of the discrete cavity resulted in the intense combustion over whole combustor length at $P=1.95$ bar and $T_{t}=2470 \mathrm{~K}$. Similar results were obtained at Mach number 3 and 3.5.

At Mach number $\mathrm{M}=3$, the intense combustion in the combustor without discrete cavity was reached only at the maximum flow parameters at the combustor entrance $\left(P=2.5\right.$ bar and $\left.T_{t}=3000 \mathrm{~K}\right)$. As in the tests with the cavity, the maximum pressure level was reached on the bottom wall but the combustion duration, which was determined from the pressure on the top and bottom walls, was approximately the same. The pressure in the base region on the top backward-facing step of the injector section was about $20 \%$ higher than in the test with solid cavity. This result can indicate fast pressure equalization in the combustion chamber under such conditions.

Analysis of time histories of pressure in the tests without and with fuel supply shows that kerosene combustion occurs in two stages. At the first stage, the static pressure started to rapidly increase at a distance exceeding $X=205 \mathrm{~mm}$ (Fig. 7). This region corresponds to the end of the channel with constant cross section. At the second stage, the position of the pressure maximum is shifted downstream. The typical pressure "gap" is situated behind the base backwardfacing step at time $t=55 \mathrm{~ms}(X=15 \mathrm{~mm})$, i. e., in the cross section behind the cavity. Duration of this "gap" was different for different cross sections of the combustor (time delay of ignition) as well as the maximum pressure level in these cross sections. The highest pressure was obtained at the end of the combustor with constant cross section (see Fig. 7). Apparently, combustion started in the local separation zone and then rapidly spread upstream and downstream along the boundary layer to the whole combustor length.

Qualitatively, the time histories of static pressure along the combustor remained the same in the tests with and without cavity. The maximum level of pressure, as well as heat fluxes on the top and bottom walls in the tests without cavity approximately corresponds to the experiments with the cavity. The distri- 


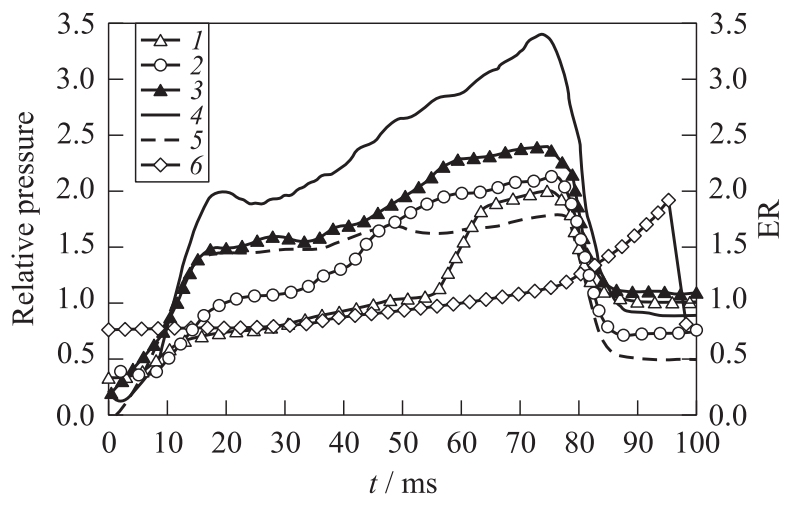

Figure 7 Process of "kindling" at kerosene combustion in the channel at $\mathrm{M}=3$ : $1-X=15 \mathrm{~mm} ; 2-55 ; 3-115 ; 4-205 ; 5-X=368 \mathrm{~mm}$; and $6-\mathrm{ER}$

bution of heat fluxes fully corresponds to the pressure distribution in the model channel. The start of the pressure rise was shifted downstream by $30-40 \mathrm{~mm}$, i. e., approximately at the cavity width. Thus, the experiments performed have demonstrated that in the no-cavity tests, the kerosene supply in the base region of the injector wedges does not guarantee effective ignition of even heated kerosene.

The data obtained allowed determining the fuel-rich flame blowout: it occurs when the fuel-air ER increases to the $\mathrm{ER}=1.2-1.4$. This limit is typical for investigated configurations of combustors with and without cavity. In spite of the fact that fuel ignition starts in different points of the combustor and at the different instants of time, combustion breakdown occurs virtually simultaneously over the whole combustor.

Investigations of propane-fuelled combustion chamber were carried out at Mach numbers 3 and 3.5 in the run with the above-mentioned flow parameters with kerosene combustion. As a result, intense combustion of propane at Mach number 3.5 was not observed under these conditions. The static pressure remained at the level of the test without fuel supply over the whole combustor length. Therefore, subsequent experiments at $\mathrm{M}=3.5$ were performed with flow parameters at the combustor entry that increased up to the maximally achievable values in a hot-shot setup. At simultaneous increase of the total temperature up to $3000 \mathrm{~K}$ and static pressure up to $2.5 \mathrm{bar}$, the local ignition occurred only at the end of the combustion chamber with the constant cross section. However, even under these parameters, the intense combustion of propane in the combustor was not realized. In this context, the possibility of propane ignition at $\mathrm{M}=3$ was checked to determine the ignition and combustion conditions. Due to the absence of propane combustion at a Mach number of 3.5, the tests were performed under higher flow parameters at the fuel entrance of the combustion chamber: 


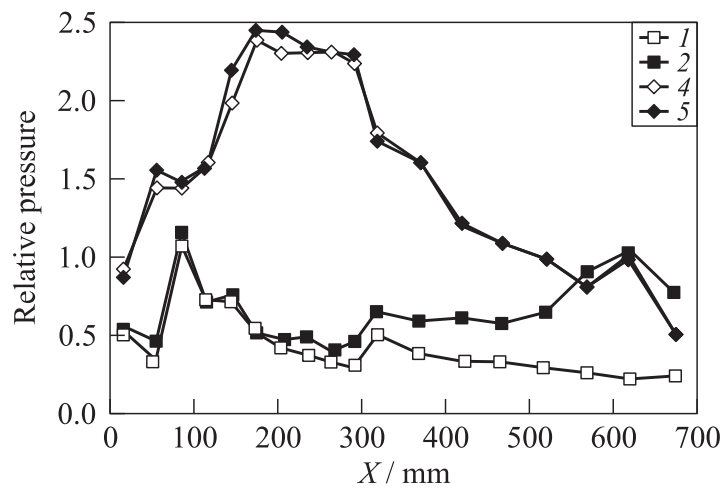

(a)

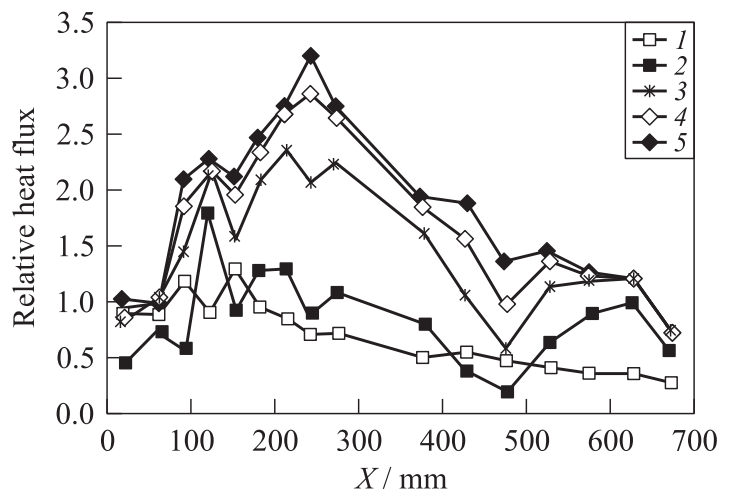

(b)

Figure 8 Static pressure $(a)$ and heat flux $(b)$ distributions along the bottom wall of the combustor at propane combustion at $\mathrm{M}_{\infty}=3: 1-$ without fuel; $2-10 \mathrm{~ms}$; $3-20 ; 4-30$; and $5-60 \mathrm{~ms}$

total temperature $T_{t}=3000 \mathrm{~K}$ and total pressure $P_{t}=1.95$ bar. The intense combustion of propane was obtained at these conditions during $60 \mathrm{~ms}$ (Fig. 8a). Here, the fast pressure growth up to the maximum value in the base region and along the whole channel should be noted. This level was kept right up to combustion breakdown. This result, perhaps, indicates high combustion efficiency during propane combustion. The decrease of the total temperature to $2700 \mathrm{~K}$ at the same static pressure led to failure of even local propane ignition.

The distribution of heat fluxes in the experiments with propane combustion conforms to the changes of static pressure in the model channel (Fig. 8b). This level of heat fluxes was kept until combustion breakdown. Comparison of the maximum heat fluxes at combustion of kerosene and propane shows that their values are approximately identical. The same conclusion can be made from the 


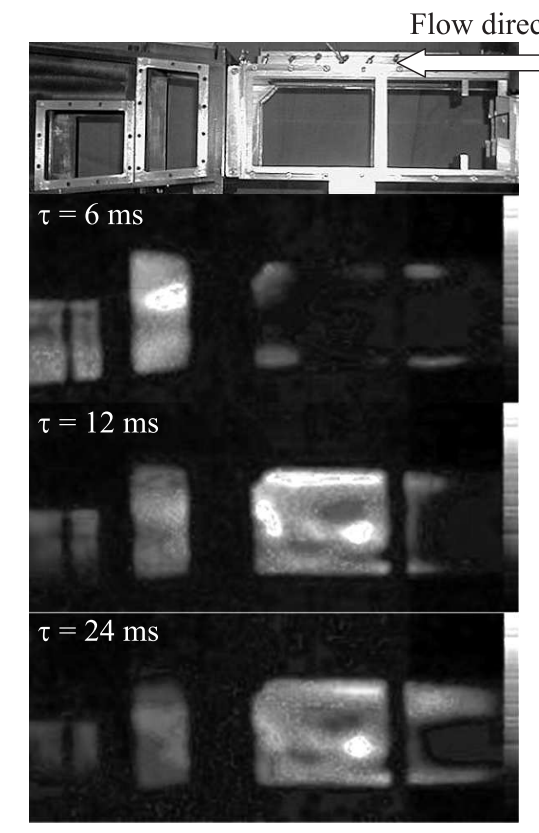

Figure 9 CH-radicals luminescence of flame, $\mathrm{M}=3.5$, discrete cavity

comparison of pressure distributions at combustion of these fuels. This result indicates that the level of combustion efficiency could be the same. At intense combustion of propane, the value of the combustion efficiency and its character of changing were somewhat different from those in the experiment with kerosene combustion. Combustion efficiency (CE) of propane increased along the channel and reached the maximum value $\mathrm{CE}=0.65$ near the exit of the combustor whereas combustion efficiency of kerosene reached the value $\mathrm{CE}=0.8$ behind the exit of the combustion channel with constant cross section. This result conforms to the distributions of pressure and heat flux in the channel. It should be noted that in the tests with the combustion chamber without cavity, the combustion efficiency did not exceed the value $\mathrm{CE}=0.55$ in the mode of intense combustion.

The obtained results ascertain that in contrast to the previously well-known data, fuel ignition in the present tests occurred not in the recirculation zone behind the backward-facing step or in the cavity but in the vicinity of the shock wave / boundary layer interaction regions on combustion chamber walls or behind these regions, nearby the combustion chamber corner point. This conclusion was confirmed by visualization of $\mathrm{OH} / \mathrm{CH}$-radicals luminescence in the channel by means of a high-speed camera. The example of such visualization of $\mathrm{CH}$-radical luminescence at combustion of kerosene at $\mathrm{M}=3.5$ is presented in Fig. 9 . 
One can see that initially, fuel self-ignition occurred in the near-wall region of the flow in the back part of combustor and then the flame propagates upstream and downstream, including propagation into the recirculation zone through the boundary layer. If the Mach number decreases, combustion intensity substantially grows not only near the cavity but also in the cavity and in the flow core that one can see in Fig. 4c. After fuel self-ignition in the recirculation zone behind the backward-facing step or behind the rear wall of the cavity, considerable rise of static pressure in the entire volume of the combustor occurs.

The study of the possible generalization and application of a criterion analysis in predicting conditions of self-ignition or combustion blowout, as well as in choosing the geometry of combustor and flame holders, is of particular interest. Evidently, under complicated conditions of supersonic 3D flow, the possibility of description of the stabilization conditions and combustion blowout is extremely important. Thus, to properly analyze the experimental results, a correlation should be chosen, which includes the largest number of the governing parameters determined from the experiments. The correlation suggested by Ozawa [40] is likely to be the most appropriate in this sense. The application of this correlation for supersonic chambers was approved and justified in [34]. The advantage of this approach consists in the combination of the breakdown characteristics of the flame with the geometric parameters of flame holders and with the gasdynamic flow structure. The disadvantage of this approach is the absence of such parameters, which explicitly account for fuel characteristics, i. e., its chemical kinetics. The type of fuel and its kinetic properties can be regarded with the aid of empirical coefficients, which should be determined from the experimental data.

To estimate the flow parameters in the recirculation zone and to consider the characteristics of the mixing layer, the stabilization parameter $\mathrm{SP}^{*}$ was calculated, using the correlation of [40]:

$$
\mathrm{SP}^{*}=\frac{\rho_{\text {rz_ref }}}{\rho_{0 \_ \text {ref }}} \frac{k_{b \_ \text {ref }}}{\tau_{\text {rz }}} \frac{14.7}{P}\left(\frac{10}{T_{t}}\right)^{1.5}
$$

where $P$ is the static pressure in the recirculation zone; $\rho_{\mathrm{rz}}$ is the gas density in recirculation zone; $T_{t}$ is the total temperature; and $\tau_{\mathrm{rz}}$ is the time of fuel residence in the recirculation zone determined in [7]. Complex $\left(\rho_{\text {rz_ref }} k_{b_{-} \text {ref }} / \rho_{0 \_ \text {ref }}\right)$ presents a correction required for the correlation of the data obtained with different flow parameters and geometry of the combustor. Using the data of [34], it has been assumed that complex ( $\left.\rho_{\text {rz_ref }} k_{b_{-} \text {ref }} / \rho_{0_{-} \text {ref }}\right)$ is equal to 1.1 and $c_{1}=0.025$ is the empirical turbulent mass transfer coefficient determining the turbulent mixing intensity.

For the conditions of intense combustion of kerosene, the values of criterion $\beta_{\mathrm{rz}}\left(\mathrm{SP}^{*}\right)$ are located in the region of stable combustion (Fig. 10). Here, $\beta_{\mathrm{rz}}$ is the ER in the recirculation zone which is calculated using the approach of [7]. In these experiments, the blowout of the intense combustion at Mach 3 is apparently related to the growth of local fuel-air ER at the end of setup operation. 


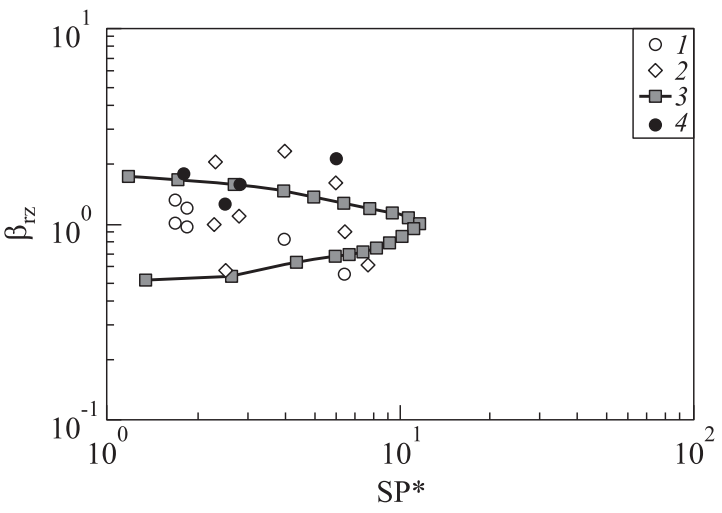

Figure 10 Blowout limits of combustion of kerosene (1-3) and propane (4): 1 and $4-\mathrm{M}=3 ; 2-\mathrm{M}=3.5$; and $3-$ Ozawa loop

The same results were obtained for intense combustion of propane: the values of $\beta_{\mathrm{rz}}\left(\mathrm{SP}^{*}\right)$ are also located inside the Ozawa's loop or nearby its border. If combustion does not occur, the Ozawa's parameter is located outside the stable combustion region.

Just like in the experiments with hydrogen [41,42], when only local fuel combustion occurs (blowoff regime), at local combustion of hydrocarbon fuels, the values of criterion $\beta_{\mathrm{rz}}\left(\mathrm{SP}^{*}\right)$ are located in the region of stable intense combustion (see Fig. 10). Such a mode was realized at Mach 3.5 in the model without cavity under the following test conditions: static pressure below 1.5 bar and total temperature below $3000 \mathrm{~K}$. In some cases, the value of $\mathrm{SP}^{*}$ in the experiments in the blowoff mode was close to the values in the experiments with the intense combustion. Such a difference in combustion pattern, under approximately the same $\mathrm{SP}^{*}$ values, can be explained by different fuel injection and mixing efficiency. In some experiments with the intense combustion, blowout takes place at local fuel-air ER much higher than that relevant to stable combustion loop for kerosene. It can be the result of inaccuracy of calculations of local fuel-air ER, which is caused by assumptions concerning the calculation of fuel penetration into the recirculation zone and by inaccuracies in calculations of the total fuel mass flow rate.

The results obtained demonstrate that the criterion by Ozawa can hardly be used to evaluate the limits of stable combustion. This conclusion is valid for the experiments with both kerosene and propane. This result may be caused by the failure to extend the two-dimensional flow relations to the 3D flows. More precise determination of combustion blowout limits (and, consequently, statistically based conclusions and recommendations) requires special experiments, which would include determining the local fuel-air ER, recirculation zone geom- 
etry, and gas parameters in this zone. Nevertheless, one can claim (as applied to the results obtained) that the correspondence between Ozawa's criterion and stable combustion region is a necessary but not sufficient condition for predicting intense combustion in combustors at supersonic speeds.

\section{CONCLUDING REMARKS}

The performed investigations showed the possibility to ensure efficient combustion of hydrocarbon fuels (kerosene and propane) at supersonic flow velocity at the combustor entrance without organizing special throttling or pseudoshocks.

The data obtained allow concluding that the application of discrete cavity speeds up the "kindling" of the combustor. It is accompanied by the significant, more than $50 \%$, growth of the pressure over the whole combustor length, including the base pressure region. At the same time, the equalization of the base pressure and the pressure on the top and bottom cavity posts (on the cavity surfaces) occurs.

The solid cavity of the studied geometry has virtually no effect on fuel ignition and combustion stabilization. This result may be explained by the absence of fuel in the cavity and by the screening effects of air and fuel jets.

The drag of the posts forming the discrete cavity was much lower (by a factor of $4-5)$ than the drag of the rear wall of the solid cavity.

One can assert (as applied to the results obtained) that there is a correspondence between Ozawa's criterion $\beta_{\mathrm{rz}}\left(\mathrm{SP}^{*}\right)$ and the region of stable combustion obtained in the experiments. However, this is shown to be a necessary but not sufficient condition for the intense combustion in the combustion chamber. This conclusion is valid for the experiments with both hydrogen and hydrocarbon fuels.

\section{ACKNOWLEDGMENTS}

This work was supported financially by the Russian Foundation for Basic Research, grant 13-08-00786.

\section{REFERENCES}

1. Curran, E. T., W.H. Heiser, and D. T. Pratt. 1996. Fluid phenomena in scramjet combustion systems. Ann. Rev. Fluid Mech. 28:323-360.

2. Billig, F. 1993. Research on supersonic combustion. J. Propul. Power 9(4):499-514.

3. Curran, E.T., and S.N.B. Murthy, eds. 2001. Scramjet propulsion. Progress in astronautics and aeronautics ser. Vol. 189. $1336 \mathrm{p}$.

4. Waltrup, P. J. 1999. Upper bounds on the flight speed of hydrocarbon-fueled scramjet-powered vehicles. AIAA Paper No. 99-7093. 
5. Vinogradov, V. A., S. A. Kobynsky, and M. D. Petrov. 1995. Experimental investigation of kerosene fuel combustion in supersonic flow. J. Propul. Power 11(1):12981305.

6. Segal, C., J. C. McDaniel, R. B. Whitehurst, and R. H. Krauss. 1995. Mixing and chemical kinetics integration in a Mach 2 reacting flow. J. Propul. Power 11(2):308314.

7. Morrison, C. Q., R. L. Campbell, and R.B. Edelman. 1997. Hydrocarbon fueled dual-mode ramjet/scramjet concept evaluation. ISABE Paper No. 97-7053:348-356.

8. Gruber, M. R., J. Donbar, C. D. Carter, and K.-Y. Hsu. 2004. Mixing and combustion studies using cavity-based flameholders in a supersonic flow. J. Propul. Power 20(5):769-778.

9. Balar, R., A. K. Gupta, K. H. Yu, and A. P. Kothari. 2007. Pylon-aided fuel injection into supersonic flow. AIAA Paper No. 2007-834.

10. Maddalena, L., T. Campioli-Shafer, and J. Schetz. 2008. Studies of the detail vortical structures in a jet in a supersonic crossflow. AIAA Paper No. 2008-87.

11. Ben-Yakar, A., and R. K. Hanson. 2001. Cavity flame-holders for ignition and flame stabilization in scramjets: An overview. J. Propul. Power 17(4):869-877.

12. Rasmussen, C. C., J. F. Driscoll, C. D. Carter, and K.-Y. Hsu. 2005. Characteristics of cavity-stabilized flames in a supersonic flow. J. Propul. Power 21(4):765-768.

13. Owens, M. G., C. Segal, and A.H. Auslender. 1997. Effects of mixing schemes on kerosene combustion in a supersonic airstream. J. Propul. Power 13(4):525-531.

14. Yu, G., J. G. Li, X. Y. Chang, L. H. Chen, and C. J. Sung. 2003. Fuel injection and flame stabilization in a liquid-kerosene-fueled supersonic combustor. J. Propul. Power 19(5):885-893.

15. Fan, X., G. Yu, J. G. Li, X. Y. Zhang, L. H. Chen, and C. J. Sung. 2006. Investigation of vaporized kerosene injection and combustion in a supersonic model combustor. J. Propul. Power 22(1):103-110.

16. Yu, K. H., K. J. Wilson, and K. C. Schadow. 2001. Effect of flame-holding cavities on supersonic-combustion performance. J. Propul. Power 17(6):1287-1295.

17. Tam, C. J., S. Cox-Stouffer, K.-C. Lin, M. Gruber, and T. Jackson. 2005. Gaseous and liquid injection into high-speed crossflows, AIAA Paper No. 2005-0301.

18. Gruber, M., C. Carter, D. Montes, L. Haubelt, P. King, and K. Hsu. 2008. Experimental studies of pylon-aided fuel injection into a supersonic cross flow. J. Propul. Power 24(3):460-470.

19. Hsu, K.-Y., C.D. Carter, M. R. Gruber, T.S. Barhorst, and U.S. Smith. 2010. Experimental study of cavity-strut combustion in supersonic flow. J. Propul. Power 26(6):1237-1246.

20. Collatz, M., M.R. Gruber, D. T. Olmstead, R. D. Branam, K.-C. Lin, and C.J. Tam. 2009. Dual cavity scramjet operability and performance study. AIAA Paper No. 2009-5030.

21. Zhang, T., J. Wang, X. Fan, and P. Zhang. 2014. Combustion of vaporized kerosene in supersonic model combustors with dislocated dual cavities. J. Propul. Power 30(5):1152-1161.

22. Kimura, I., H. Aoki, and M. Kato. 1981. The use of a plasma jet for flame stabilization and promotion of combustion in supersonic airflows. Combust. Flame 42(10):297-305.

23. Wagner, T.C., W.F. O'Brien, G.B. Northam, and J. M. Eggers. 1989. Plasma torch ignition for scramjets. J. Propul. Power 5(5):548-554. 
24. Bonghi, L., M. J. Dunlap, M. Owens, C. D. Young, and C. Segal. 1995. Hydrogen piloted for supersonic combustion of liquid fuels. AIAA Paper No. 95-0730.

25. Jacobsen, L. S., S. D. Gallimore, W. F. O'Brien, and J. A. Schetz. 2003. Integration of an aeroramp injector/plasma-igniter for hydrocarbon scramjets. J. Propul. Power 19(2):170-182.

26. Grady, N., R. W. Pitz, C. D. Carter, K.-Yu. Hsu, C. Godke., and S. Menon. 2012. Supersonic flow over a ramped wall cavity flame holder with an upstream strut. J. Propul. Power 28(5):982-990.

27. Yungster, S., A. Suresh, M. E. M. Stewart, and J. Lee. 2005. A study of ram combustor performance using 1D and 3D numerical simulations. AIAA Paper No. 2005430.

28. Rajasekaran, A., and V. Babu. 2006. Numerical simulation of three dimensional reacting flow in a model supersonic combustor. J. Propul. Power 22(4):820-827.

29. Malo-Molina, F., D. Gaitonde, H. Ebrahimi, and S. Ruffin. 2006. Numerical simulation of a generic high-speed inlet/combustor with hydrocarbon fuel. AIAA Paper No. 2006-4683.

30. Ebrahimi, H. B., D. V. Gaitonde, and F. J. Malo-Molina. 2007. Parametric study of 3-D hydrocarbon scramjet engine with cavity. AIAA Paper No. 2007-645.

31. Battista, F., L. Cutrone, G. Ranuzzi, and S. Borreca. 2008. Supersonic combustion models application in advanced propulsion concepts, AIAA Paper No. 2008-2553.

32. Kumaran, K., and V. Babu. 2009. Mixing and combustion characteristics of kerosene in a model supersonic combustor. J. Propul. Power 2(3):583-591.

33. Ladeinde, F. 2009. A critical review of scramjet combustion simulation. AIAA Paper No. 2009-127.

34. Morrison, C., H.-Y. Lyu, and R. Edelman. 1999. Fuel sensitivity studies based on a design system for high speed airbreathing combustors. ISABE Paper No. 99-7235.

35. Mathur, A. B., P. J. Ortwerth, V.A. Vinogradov, V.T. Grin, M. A. Goldfeld, and A. V. Starov. 1996. Experimental and numerical investigation of hydrogen and ethylene combustion in a Mach 3-5 channel with a single injector. AIAA Paper No. 1996-3245.

36. Mathur, A. B., M. A. Goldfeld, R. V. Nestoulia, and A. V. Starov. 2001. Investigation of base pressure behind the injector section in a supersonic combustion chamber. 2001. ISABE Paper No. 2001-0024.

37. Northam, G. B., I. Greenberg, C. S. Byington, and D. P. Capriotti. 1998. Evaluation of parallel injector configurations for Mach 2 combustion. J. Propul. Power 8(2):491-499.

38. Pusyrev, L. N., and M. I. Yaroslavtsev. 1990. Stabilization of gas parameters in prechamber of hypersonic hot shot wind tunnel. Izv. Acad. Nauk 2(5):93-102. (In Russian.)

39. Goldfeld, M. A., A. V. Starov, K. Yu. Timofeev, and V. A. Vinogradov. 2009. Ignition process evolution at high supersonic velocities in channel. J. Therm. Sci. 18(2):166-173.

40. Ozawa, R. I. 1971. Survey of basic data of flame stabilization and propagation for high speed combustion systems. AFARL-TR-70-81:1-39.

41. Ortweth, P. J., A. B. Mathur, C. Segal, and S. Mullagilli. 1999. Combustion stability limits of hydrogen in non-premixed supersonic flow. ISABE Paper No. 99-7136.

42. Starov, A. V. 2007. Determination of stable combustion limits at high supersonic flow velocity in channel. Bull. Novosibirsk State University. Phys. 3(2):47-60. (In Russian.) 